\title{
A NEW FISH SPECIES OF THE INDO-BURMESE GENUS BADIS BLEEKER (TELEOSTEI: PERCIFORMES) FROM MANIPUR, INDIA
}

\author{
W. Vishwanath ${ }^{1}$ and K. Shanta
}

Department of Life Sciences, Manipur University, Canchipur, Manipur 795003, India

Email:1 vnath_w@hotmail.com

web supplement

\section{Abstract}

A new species of genus Badis is described from the tributaries of Barak in Manipur. The species has a conspicuous black blotch covering the superficial part of the cleithrum above pectoral fin base, a black blotch between $3^{\text {rd }}$ and $4^{\text {th }}$ dorsal spine, a mid basal rounded black spot on caudal fin; 20 circumpeduncular scales, 31 vertebrae; 26-32 scales in lateral row. The species differs from Badis kanabos and $\mathrm{B}$. badis by its narrower interorbital width and shallower body. It also differs from $\mathrm{B}$. kanabos in having more circumpeduncular scales and from $\mathrm{B}$. badis and $\mathrm{B}$. chittagongis in having more vertebrae.

\section{KEYWORDS}

Badis tuivaiei sp. nov., fish, India, Manipur

Hamilton (1822) described Labrus badis from Gangetic provinces and distinguished it from Labrus dario of northern parts of Bihar and Bengal in having 17 vs. 14 dorsal spines and a lateral line vs. without lateral line. Bleeker (1854) established genus Badis for Labrus badis under family Nandidae. He distinguished the new genus from genus Nandus in having a smooth and serrated preopercular margin and edentulous and toothed tongue. Kullander and Britz (2002) made a thorough revision of the genus and defined the genus with the characteristics: tubed lateral line scales, 2-4 dentary foramina, hypobranchial 3-toothed, males with short pelvic fin not reaching the first dorsal spine, males with short dorsal fin lappets and rounded caudal fin, black stripe along middle of dorsal fin, dark bars on trunk modified in adults each displaying as two narrow vertical lines, dark pigment on caudal fin base differentiated into three vertically aligned blotches. The revision recognizes twelve species (distributed from Indus in the west to Mekong in the east), including eight new species, i.e., one from Ganges deltaic region, two from Brahmaputra basin, four from Chindwin-Irrawady basin and one from Mae Nam Khwai Noi basin. The authors also mentioned that no material of Badis was available from the region between Bangladesh and Myanmar through adjacent Indian states which may be due to insufficient collecting. Vishwanath et al (1998) reported Badis sp. from Chatric and Lokchao rivers, both from Chindwin basin, however, did not mention species name.

A few fish collection trips were conducted along the tributaries of the Barak in Manipur. The river flows out of Manipur finally to enter Bangladesh and join the Meghana, a tributary of the Ganges. The collections included 26 specimens of Badis which do not fit into hitherto described species. The fish is described herein as new species.

\section{Materials ANd Methods}

Measurements and counts followed Kullander \& Britz (2002). Dial caliper with sharp tips was used for measurements up to the nearest $0.1 \mathrm{~mm}$ and expressed as percentages of standard length (SL). All counts were done using a stereo zoom microscope. Type specimens were deposited in the Manipur University Museum of Fishes (MUMF).

\section{Badis tuivaiei sp. nov.}

(Fig. 1)

\section{Materials examined}

Holotype: 9.viii.2000, Tuivai River, Churachandpur District, Manipur, 34.6mm SL, coll. K. Shanta, MUMF 5124

Paratypes: 20 exs., data as holotype, 26.4-54.0mm SL, MUMF 5115/20; 2 exs.,25.vii.2000, both from Tuivai River, Churachandpur District, Manipur, coll. Juliana L., MUMF 5116 (49.00mm SL), MUMF 5118 (30.2mm SL); 3 exs., 3.ii.2004, Irang R. Tamenglong District, Manipur, 53.5-59.4mm SL, coll. L. Shakuntala, MUMF 5125-5127.

\section{Etymology}

The species is named after the Tuivai River from which the holotype was collected.

\section{Diagnosis}

A Badis species with the following combination of characters: a conspicuous black blotch covering the superficial part of the cleithrum above pectoral fin base, a black blotch between $3^{\text {rd }}$ and $4^{\text {th }}$ dorsal spine, a mid basal rounded black spot on caudal fin; 20 circumpeduncular scales, 31 vertebrae; $26-32$ scales in lateral row and interorbital width, and body depth respectively 5.6-6.6\% and $25.9-29.2 \%$ of SL.

\section{Description}

General aspect is in Figure 1 (see also colour Image $1^{\mathrm{w}}$ ). Morphometric data as in Table 1 frequency distribution of meristic characters in Table 2 and comparison with related species in Tables 3. Body elongate, moderately compressed. Predorsal contour straight in small specimens, sloping at some angle as prepelvic contour in some larger specimens, more strongly as the size increases. Orbit situated in anterior half of head and at about mid axis of body. Jaws almost equal anteriorly, lower jaw slightly projecting, maxilla reaching to $1 / 3$ of orbit. Opercular spine slender with a simple sharp tip. Palatine, vomer and parasphenoid toothed. Dental pores 3; anguloarticular pores 2; preopercular pores 6 ; nasal pores 2 ; supraorbital pores 3 ;

${ }^{w}$ see Image 1 of the fish in the web supplement at www.zoosprint.org 
Table 1. Proportional measurements and counts of Badis tuivaiei sp. nov. in percentage of standard length except standard length. In case of counts of paratypes, model number, maximum and minimum numbers are given. Model number is the maximum number after frequency distribution analysis.

\begin{tabular}{|c|c|c|c|c|c|}
\hline \multirow[b]{2}{*}{ Proportional Mesurements } & \multicolumn{2}{|c|}{ Holotype } & \multicolumn{2}{|c|}{ Paratypes } & \multirow[b]{2}{*}{ S.D. } \\
\hline & & Mean & Min. N & Max. & \\
\hline Standard length (mm) & 34.6 & 26.4 & \multicolumn{2}{|l|}{59.4} & \\
\hline Head length & 10.4 & 28.2 & 26.03 & 31.4 & 1.7 \\
\hline Snout length & 2.4 & 7.0 & 6.1 & 7.6 & 0.4 \\
\hline Orbital diameter & 3.0 & 7.5 & 6.1 & 9.4 & 1.0 \\
\hline Interorbital width & 2.3 & 6.4 & 5.6 & 7.2 & 0.5 \\
\hline Upper jaw length & 2.5 & 8.9 & 8.5 & 10.4 & 0.7 \\
\hline Lower jaw length & 4.3 & 13.9 & 10.91 & 16.4 & 1.5 \\
\hline Body depth & 9.7 & 27.7 & 25.92 & 29.2 & 0.9 \\
\hline Pelvic fin length & 8.6 & 23.8 & 20.92 & 25.8 & 1.4 \\
\hline Pelvic to anal fin distance & 10.8 & 32.9 & $29.8 \quad 3$ & 36.7 & 2.4 \\
\hline Counts & \multicolumn{2}{|c|}{ Model No } & \multicolumn{2}{|l|}{ Min. } & Max. \\
\hline $\mathrm{D}$ & $18 / 9$ & $18 / 9$ & $16 / 9$ & & $18 / 9$ \\
\hline $\mathrm{P}$ & 13 & 13 & 13 & & 14 \\
\hline$A$ & iii, 7 & $7-8$ & 6 & & 10 \\
\hline Lateral scale rows & 30 & 30 & 26 & & 32 \\
\hline Lateral line count & $23 / 4$ & $24 / 4$ & $20 / 2$ & & $25 / 4$ \\
\hline Lateral transverse scales & $11 / 2 / 1 / 7$ & $11 / 2 / 1 / 7$ & $11 / 2 / 1 / 7$ & & $11 / 2 / 1 / 7$ \\
\hline Circumpeduncular scales & 20 & 20 & 16 & & 20 \\
\hline Gill rakers & 6 & 6 & 6 & & 8 \\
\hline Vertebrae & 31 & & & & \\
\hline
\end{tabular}

Table 2. Frequency distribution of meristic characters

a. Dorsal fin counts (spines/soft rays)

\begin{tabular}{llllll}
\hline Counts & $16 / 9$ & $16 / 10$ & $17 / 8$ & $\begin{array}{l}18 / 8 \\
2\end{array}$ & $\begin{array}{l}18 / 9 \\
18\end{array}$ \\
Specimens & 1 & 1 & 4 & 2 & \\
\hline b. Anal fin counts & & & & \\
\hline Counts & 6 & 7 & 8 & 9 & 10 \\
Specimens & 3 & 12 & 6 & 4 & 1 \\
\hline
\end{tabular}

c. Pectoral fin counts

Counts $13 \quad 14$

Specimens $22 \quad 4$

d. Lateral scale rows

\begin{tabular}{llllllll}
\hline Counts & 26 & 27 & 28 & 29 & 30 & 31 & 32 \\
Specimens & 3 & - & 2 & 5 & 10 & 4 & 2 \\
\hline
\end{tabular}

e. Lateral line scale counts (upper/lower scales)

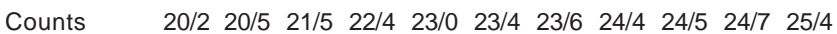
$\begin{array}{llllllllllll}\text { Specimens } & 1 & 2 & 1 & 1 & 4 & 2 & 2 & 8 & 1 & 2 & 2\end{array}$

\section{f. Gill raker}

\begin{tabular}{llll}
\hline Counts & 6 & 7 & 8 \\
Specimens & 3 & 2 & 2
\end{tabular}

$2 \quad 2$

g. Vertebrae number

Counts 16/14 16/15

Specimens $2 \quad 5$ extrascapular pores 2; supracleithral pores 2; posttemporal pores 2 ; coronalis pore 1 ; lachrymal pores 3 ; row of free neuromasts extending across gap between lachrymal and anterormost infraorbital; infraorbital pores 3-4.

Scales on sides strongly ctenoid. Scales on top of head cycloid. Predorsal scales 4-5 anterior to coronalis pore, posteriorly 8-9; 3-4 scales on cheek, mostly ctenoid, a few anterior scales cycloid. Circumpeduncular scale rows 9 above, 9 below lateral lines, totaling 20. Scales in vertical row $1 \frac{1 / 2}{2}$ above, 7 below lateral lines.

Soft dorsal and anal fins with rounded tips, reaching to almost about $1 / 3$ or $1 / 4$ of caudal fin. Caudal fin rounded. Pectoral fin rounded, extending about $2 / 3$ distance to anal fin origin. Pelvic fin pointed, inner branch of second soft ray the longest, not reaching to vent.

\section{Colour}

In formaline: pale brownish to yellowish with brown to black markings. Preorbital stripe dark grey continued across chin. Postorbital stripe blackish, formed by a single blotch close to orbit; dark pigment also on one scale posterior to that blotch. No supraorbital stripe. Brownish suborbital stripe, continued fainter across underside of head. No opercular blotch. Prominent, dark brown cleithral blotch. Ventral and underside of head notably duskied, otherwise ventral aspect lighter than sides.

Dorsal fin dusky. A black blotch at base between $3^{\text {rd }}$ and $5^{\text {th }}$ spine is present in specimens measuring $25 \mathrm{~mm}$ SL and more. It may be absent in some. Bars on body usually end in two black blotches on scaly basal cover of dorsal fin. Dorsal fin lappets white along distal margin, bordered by blackish submarginal stripe. In larger specimens, soft dorsal and anal fins and caudal fin uniformly brown; in small specimens, soft fins hyaline. Caudal fin with a small rounded brownish blotch at middle of base, also covering last lateral scale on body, usually also a brown vertical bar covering fin base, occasionally absorbing caudal base spot entirely. Anal fin dusky basally, soft part hyaline or dark throughout in large specimens. Pelvic fin dusky in small specimens; dark brown in large specimens.

\section{Geographcal distribution}

Tuivai and Irang rivers, both tributaries of the Barak in Manipur. Inhabits clear water montane streams.

\section{Discussion}

Badis tuivaiei is similar to B. kanabos Kullander \& Britz (2002), B. chittagongis Kullander \& Britz (2002) and B. badis (HamiltonBuchanan, 1822) in their colour patterns, particularly the horizontal lines on sides and blotch on caudal peduncle. The new species, however differs from $B$. kanabos by its narrower interorbital width (5.6-6.6 vs. 7.3-8.6), shallower body (25.9-29.2 vs. 29.0-35.0), more lateral scale rows (26-32 vs. 25-26), more circumpeduncular scales (20 vs. 16-17), more vertebrae (30-31 vs. 26-28) and more dorsal fin rays (xviii, 9 vs. xvi, 9).

It is also distinguished from Badis badis in its narrower 
Table 3. Comparison of proportional measurements in percentage of standard length and counts of Badis tuivaiei sp. nov. with related species

\begin{tabular}{lllll}
\hline Proportions & B. tuivaiei sp. nov. & B. chittagonsis & B. badis & B. kanabos \\
\hline Body depth & $25.9-29.2$ & $29-34$ & $30.7-38.9$ & $29-35$ \\
Interorbital width & $5.6-6.6$ & $5.5-6.7$ & $6.5-8.3$ & $7.3-8.6$ \\
\hline Counts & & & & \\
\hline Dorsal fin rays & $18 / 9(16 / 9-18 / 9)$ & $17 / 9(16 / 9-18-9)$ & $16 / 9(15 / 9-18 / 9)$ & $16 / 9(15 / 9-17 / 9)$ \\
Pectoral fin rays & $13(13-14)$ & $13(12-14)$ & $12(11-14)$ & $12(11-13)$ \\
Anal fin rays & $7(6-10)$ & $7(6-9)$ & $7(6-8)$ & $7(6-8)$ \\
Lateral scale rows & $30(26-32)$ & $27(27-29)$ & $26(25-28)$ & $26(25-26)$ \\
Lateral line scales (upper/lower) & $24 / 4(20 / 2-25 / 4)$ & $21 / 4(20 / 3-24 / 6)$ & $21 / 4(17 / 1-24 / 4)$ & $22 / 4(20 / 3-22 / 4)$ \\
Circumpeduncular scales & $20(16-20)$ & 20 & $19-20$ & $16-17$ \\
Gill rakers & $6(6-8)$ & $9(8-11)$ & $7(5-9)$ & $6-7$ \\
Vertebrae & $31(30-31)$ & $28(28-29)$ & $27(26-28)$ & $27(26-28)$ \\
\hline
\end{tabular}

interorbital width (5.6-6.6 vs. 6.5-8.3) more pectoral fin rays (13 vs. 12), more lateral row scales (26-32 vs. $25-27)$, and more vertebrae (31 vs. 27).

It is also distinguished from Badis chittagongis in having more lateral scale rows (26-32 vs. 27-29) and more vertebrae (31 vs. 28). It also differs from B. ferrarisi (Kullander \& Britz, 2002) in presence of distal extrascapular.

\section{REFERENCES}

Hamilton-Buchanan, F. (1822). An account of the fishes found in the river Ganges and its tributaries. Edinburg \& London, vii+405pp.
Bleeker, P. (1854). Nalezingen op de ichthyologische fauna van Bengalea en Hindostan. Verhandel. Batav. Genootsch. Kunst. Wetensch.: 25(8): 1166.

Vishwanath, W., W. Manojkumar, L. Kosygin and K.S. Selim (1998). Biodiversity of freshwater fishes of Manipur, India. Italian Journal of Zoology 65(Supplementary): 64-69.

Kullander, S.O. and R. Britz (2002). Revision of the family Badidae (Teleostei: Perciformes), with description of a new genus and ten new species. Ichthyological Exploration of Freshwaters 13(4): 295-372.

\section{ACKNOWLEDGEMENTS}

Our thanks are due to Dr. S.O. Kullander (Swedish Museum of Natural Histroy, Stockholm) for literature, NBFGR (National Bureau of Fish Genetic Resources, Lucknow) for financial assistance through ICAR-NATP.

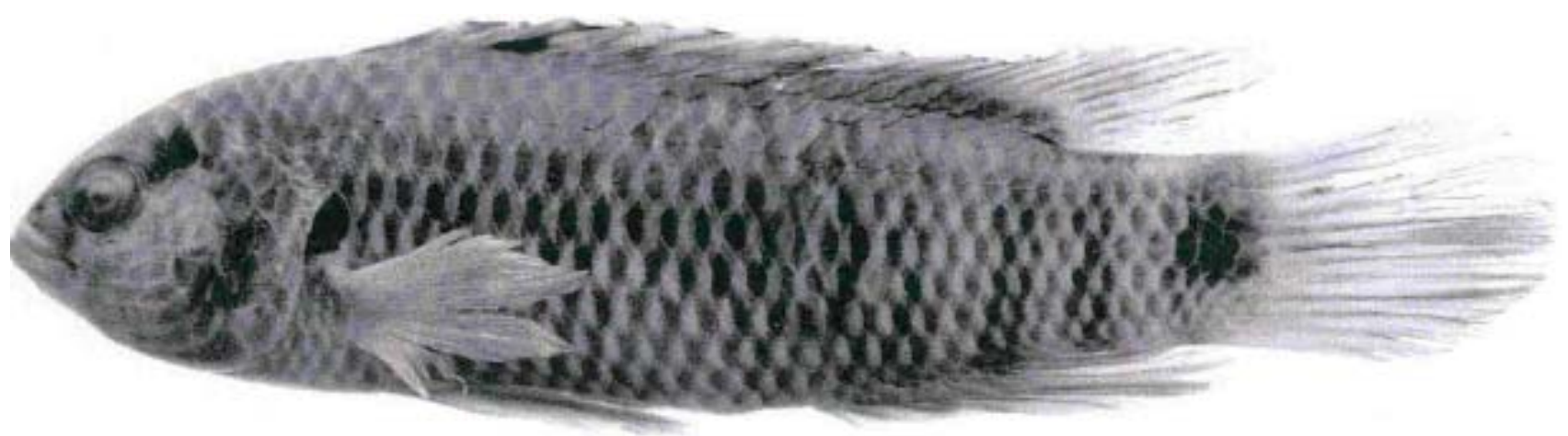

Figure 1. Badis tuivaiei sp. nov. 